\title{
A complication of trans-septal puncture during VT ablation: clinical application of transoesophageal echocardiography in interventional procedures
}

\author{
Elena Assimakopoulou, ${ }^{1}$ Orathi Sanjay, ${ }^{1}$ Stephen Murray, ${ }^{2}$ Stephan Schueler ${ }^{3}$ \\ ${ }^{1}$ Department of Cardiothoracic Anaesthesia, Freeman Hospital, Newcastle Upon Tyne, UK \\ ${ }^{2}$ Department of Cardiology, Freeman Hospital, Newcastle Upon Tyne, UK \\ ${ }^{3}$ Department of Cardiothoracic Surgery, Freeman Hospital, Newcastle Upon Tyne, UK
}

Correspondence to Dr Elena Assimakopoulou, elena.assimakopoulou@nuth.nhs.uk, asimakopoulou.elena@yahoo.gr

\section{DESCRIPTION}

Trans-septal puncture is a routine approach in most electrophysiology laboratories since atrial fibrillation (AF) and ventricular tachycardia (VT) ablation became common. Here, we report a procedural complication and its safe resolution.

A 68-year-old man was brought in and admitted urgently in our department after sudden onset of palpitations. His medical history included coronary artery bypass graft (CABG), bundle branch block, AF, implanted implantable cardioverter defibrillator (ICD) and episodes of recurrent VT documented after electrophysiological study. From his ICD log it was obvious that he suffered a self-terminated episode of VT. On admission he was haemodynamically stable with a systolic pressure of $110 \mathrm{~mm} \mathrm{Hg}$, and had elevated international normalized ratio (INR) (3.1) due to warfarin therapy for his AF To counter this, 3000 units of human

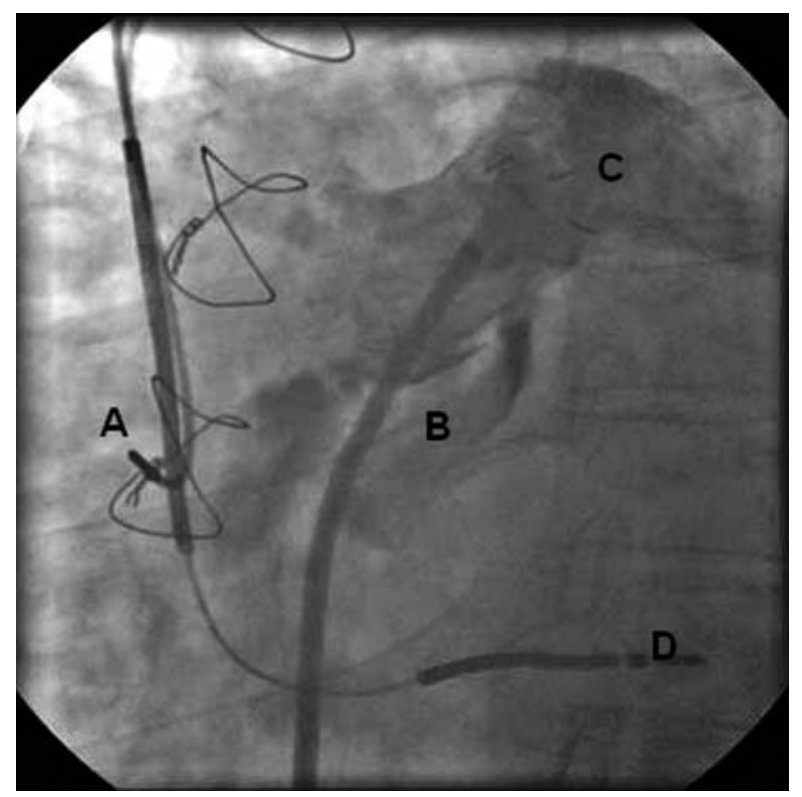

Figure 1 Fluoroscopic left anterior oblique view of the right pulmonary artery with contrast in situ. $A$, right atrium with atrial lead in situ in right atrial appendage; $B$, left atrium, lying beneath the main pulmonary trunk; $C$, the main pulmonary artery trunk; $D$, right ventricular apex with ICD lead in situ. prothrombin complex and $5 \mathrm{mg}$ vitamin $\mathrm{K}$ were instituted intravenously and the INR was reduced to 1.2 .

The technique described by Linker and Fitzpatrick ${ }^{1}$ was used. In the cardiac interventional laboratory under fluoroscopic guidance, contrast was injected to confirm the position of the fossa ovalis and the intra-atrial septum was punctured. However, on advancing the sheath it became evident that it had punctured the left atrial roof and entered the right pulmonary artery (RPA). Figure 1 demonstrates the left anterior oblique view of the RPA with contrast in situ.

The procedure was stopped due to this complication. A stiff guide wire was passed across the puncture site prophylactically to counter any untoward bleeding. A decision was taken to transfer the patient to the operation theatre to withdraw the sheath in a controlled environment. Under general anaesthesia and invasive monitoring a transesophageal echocardiography (TOE) probe was inserted to evaluate cardiac anatomy, to assess flow across the perforation and to detect possible pericardial effusion. The ablation sheath was withdrawn under direct TOE imaging (figure 2). The procedure was carried out in the presence of a cardiothoracic surgeon and a perfusionist ready to proceed with opening the chest in the

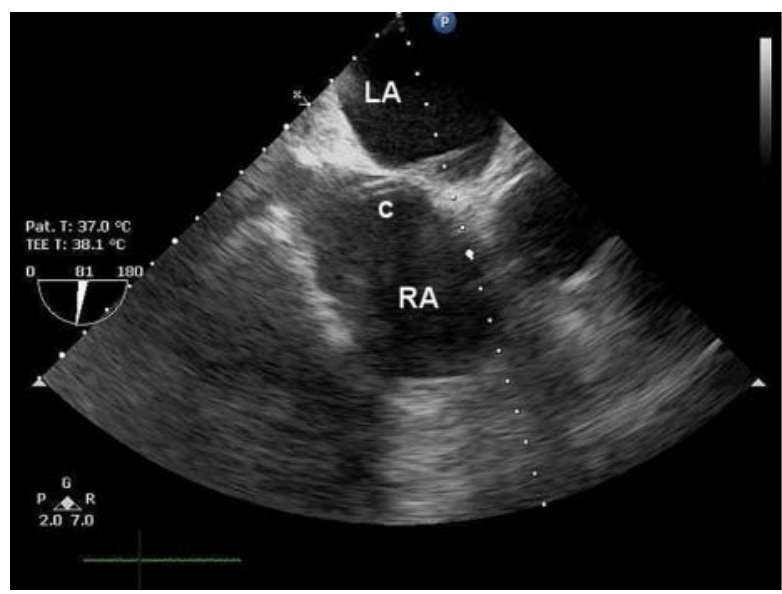

Figure 2 Transesophageal echocardiography image of the ablation catheter sheath (c) across the interatrial septum. LA, left atrium; RA, right atrium. 


\section{BMJ Case Reports}

case of massive pericardial effusion. The sheath removal was uneventful. The result of follow-up of this connection was healing with no sequelae.

\section{Learning point}

- TOE has become the gold standard modality to monitor several non-coronary interventional procedures owing to its versatility in real-time visualisation of cardiac structures, catheters and devices. ${ }^{2}$

\section{Competing interests None}

Patient consent Obtained.

\section{REFERENCES}

1. Linker NJ, Fitzpatrick AP. The transseptal approach for ablation of cardiac arrhythmias: experience of 104 procedures. Heart1998;79:379-82.

2. Balzer J, Kelm M, Kuhl HP. Real time three dimensional transoesophageal echocardiography for guidance of non coronary interventions in the catheter laboratory. Eur J Echocardiogr 2009;10:341-9.

This pdf has been created automatically from the final edited text and images.

Copyright 2012 BMJ Publishing Group. All rights reserved. For permission to reuse any of this content visit http://group.bmj.com/group/rights-licensing/permissions.

BMJ Case Report Fellows may re-use this article for personal use and teaching without any further permission.

Please cite this article as follows (you will need to access the article online to obtain the date of publication).

Assimakopoulou E, Sanjay 0, Murray S, Schueler S. A complication of trans-septal puncture during VT ablation: clinical application of transoesophageal echocardiography in interventional procedures. BMJ Case Reports 2012;10.1136/bcr.01.2012.5700, Published XXX

Become a Fellow of BMJ Case Reports today and you can:

- Submit as many cases as you like

- Enjoy fast sympathetic peer review and rapid publication of accepted articles

- Access all the published articles

- Re-use any of the published material for personal use and teaching without further permission

For information on Institutional Fellowships contact consortiasales@bmjgroup.com

Visit casereports.bmj.com for more articles like this and to become a Fellow 